Finisterra, XXXVI, 71, 2001, pp. 83-101

\title{
DESENVOLVIMENTO DE UM MICROEROSÓMETRO DO TIPO TMEM PARA APLICAÇÃO EM PLATAFORMAS ROCHOSAS LITORAIS
}

\author{
MÁrio NEVES ${ }^{1}$ \\ ANA Ramos Pereira ${ }^{2}$ \\ MANUEla LARANJEIRA ${ }^{3}$ \\ JORGE TRINDADE ${ }^{4}$
}

\begin{abstract}
Resumo - A determinação da taxa de erosão das plataformas rochosas litorais necessita de equipamento específico, adaptado às condições ambientais em que se desenvolvem estas plataformas. Neste trabalho, descreve-se a concepção de equipamento adaptado a esse fim - um microerosómetro do tipo TMEM (Traversing Micro-Erosion Meter) - ao qual foram introduzidas algumas modificações, que visam melhorar quantitativa e qualitativamente os dados a obter. São também indicados, para além das vantagens e limitações deste equipamento, os procedimentos principais seguidos nas fases de instalação e medição com o TMEM. Referem-se ainda os primeiros resultados obtidos num ensaio experimental levado a cabo numa plataforma calcária situada nos Tombadoiros, a norte da Ericeira, entre os níveis mínimo da preiamar morta e o nível máximo da preiamar viva. Os resultados correspondem a 96 dias de evolução entre duas observações no período de Outono/Inverno de 2000/2001 e apontam para uma taxa de rebaixamento médio da plataforma rochosa de $0,153 \mathrm{~mm} / \mathrm{ano}$. A cobertura pelo líquene Verrucaria maura de mais de metade dos pontos de medição condicionou, no entanto, os resultados obtidos, tendo a separação destes em dois grupos permitido concluir que o sector de rocha limpa apresentou uma taxa de erosão 2,5 superior à do sector coberto por aquele líquene.
\end{abstract}

Palavras-chave: plataforma rochosa litoral, microerosómetro, taxas de rebaixamento, Estremadura portuguesa

Abstact - Development and application of a Traversing Micro-Erosion Meter FOR SHORE PLATFORMS - The study of the shore platforms specific environmental conditions requires accurate equipment to measure erosion rates. In this paper, the construction details of a Traversing Micro-Erosion Meter (TMEM) is described. This TMEM adds some improvements to previous devices that aim to increase the

1,2,3 Investigadores/ ${ }^{4}$ Colaborador do Centro de Estudos Geográficos - Linha de Investigação DILIF (Dinâmica Litoral e Fluvial)

1 Assistente da Universidade de Lisboa. E-mail: mario.neves@ceg.ul.pt

2 Professora Associada da Universidade de Lisboa. E-mail: anarp@mail.doc.fl.ul.pt

3 Assistente da Universidade do Minho. E-mail: manela_laranjeira@yahoo.com

4 E-mail: jmrtrindade@clix.pt 
data set collected, both in quality and in quantity. The installation and measurement procedures are described, as well as the advantages and limitations of this equipment. An experimental survey was carried out within the tidal range of the limestone shore platform of Tombadoiros, in a sector of the Portuguese western coast. For a 96 days period in the autumn/winter of 2000/2001, the mean rate of erosion at the site was $0,153 \mathrm{~mm} /$ year. However, this result includes disturbances associated with the settlement of the black lichen Verrucaria maura in $58 \%$ of the measuring points. It was found that the mean rate of erosion in the clean rock surface was 2,5 higher when compared to the area colonized by the lichen.

Key words: shore platforms, micro erosion meter, downwearing rates, Portuguese western coast

\section{INTRODUÇÃO}

Nas últimas décadas, a investigação sobre a evolução actual dos litorais rochosos tem seguido a tendência geral da Geomorfologia para a utilização de métodos quantitativos que permitam caracterizar e comparar, de uma forma mais exacta, a dinâmica deste tipo de litorais. Dado que os litorais rochosos são constituídos essencialmente por formas erosivas, o desenvolvimento destes estudos privilegiou fundamentalmente a criação e aperfeiçoamento de instrumentação destinadas, em particular, à medição da erosão.

Nesse sentido, a maior parte da atenção tem sido dirigida para a determinação da taxa de erosão no topo das arribas, não só porque o recuo destas apresenta geralmente valores que são mensuráveis recorrendo a técnicas relativamente simples (como medições no terreno entre referências fixas pré-existentes ou instaladas e o topo da arriba ou a comparação de fotografia aérea ou terrestre), mas também porque a sua evolução tem uma aplicação prática imediata, já que condiciona o uso específico desta parte do território litoral. Pelo contrário, o estudo quantitativo da erosão da plataforma rochosa, no sopé da arriba não tem sido objecto de muitos trabalhos de investigação. Este facto, contudo, não é de estranhar. As plataformas rochosas litorais localizam-se num meio periodicamente coberto pelas águas do mar, correspondendo frequentemente esses períodos a fases de elevado hidrodinamismo. A conjugação destes dois factores torna muito complicada a instalação de equipamento fixo de medição. Por outro lado, o rebaixamento destas plataformas não apresenta um dinamismo que permita a utilização de metodologias mais convencionais como as desenvolvidas para o recuo das arribas. O ritmo de evolução das plataformas rochosas litorais torna pois necessária a utilização de equipamento de medida com uma elevada resolução.

Pretende-se, neste artigo, descrever detalhadamente equipamento desenvolvido com o objectivo específico de determinar a taxa de rebaixamento das plataformas rochosas litorais, bem como os primeiros resultados obtidos da sua aplicação. 


\section{TRABALHOS ANTERIORES}

Os estudos pioneiros tendentes à determinação da taxa de erosão das plataformas rochosas utilizaram métodos indirectos de cálculo (Quadro I). Em 1941, Emery, citado por STEPHENSON (2000), terá determinado esta taxa na California, deduzindo a erosão a partir de inscrições datadas na rocha. O biólogo W. North, referido por KIRK (1977), publicou, em 1954, os resultados da medição do volume de resíduos fecais dos organismos vivos do género Littorina sp., que arranham e esfolam a rocha para procurar fungos, líquenes e algas que constituem a sua alimentação para, a partir daí, inferir uma taxa de erosão da plataforma rochosa. REVELLE e EMERY (1957) utilizaram outro método, determinando a taxa de rebaixamento de plataformas talhadas em rochas calcárias, baseados na análise química da água das poças e, em particular, na variação dos valores de dissolução e precipitação química. O primeiro trabalho de investigação, em que se tentou medir directamente a erosão das plataformas rochosas, foi efectuado por HodGKINS (1964), tendo este investigador australiano determinado a variação de massa de exemplares de rocha fixados na plataforma rochosa durante um período de nove anos.

QUADRO I - Principais trabalhos publicados até 1970 contendo valores de taxa de rebaixamento de plataformas rochosas litorais

(adaptado de KIRK, 1977)

TABLE I-Main published erosion rates on shore platforms before 1970

(modified from KIRK, 1977)

\begin{tabular}{|l|l|c|l|l|}
\hline \multicolumn{1}{|c|}{ Autor } & \multicolumn{1}{|c|}{ Metodologia } & $\begin{array}{c}\text { Taxa de } \\
\text { rebaixamento } \\
\left(\mathrm{mm}^{-1} \mathbf{a n o}^{-1}\right)\end{array}$ & \multicolumn{1}{|c|}{ Litologia } & \multicolumn{1}{|c|}{ Localização } \\
\hline Emmery (1941) & Desgaste de inscrições datadas & 0,3 & $\begin{array}{l}\text { Arenitos } \\
\text { calcários }\end{array}$ & $\begin{array}{l}\text { La Jolla, Cali- } \\
\text { fornia, EUA }\end{array}$ \\
\hline North (1954) & $\begin{array}{l}\text { Volume de resíduos fecais de gastró- } \\
\text { podes }\end{array}$ & 0,6 & $\begin{array}{l}\text { Arenitos } \\
\text { de praia }\end{array}$ & $\begin{array}{l}\text { California, } \\
\text { EUA }\end{array}$ \\
\hline Revelle e Emery (1957) & Análise química da água das poças & 0,3 & Calcários & $\begin{array}{l}\text { Bikini Atoll, } \\
\text { Ilhas Marshall }\end{array}$ \\
\hline Hodgkins (1964) & $\begin{array}{l}\text { Comparação do peso de blocos rochosos } \\
\text { fixados na plataforma rochosa litoral ao } \\
\text { longo de 9 anos }\end{array}$ & $0,6-1,0$ & Calcários & $\begin{array}{l}\text { Ilhas Norfolk, } \\
\text { Austrália }\end{array}$ \\
\hline Evans (1969) & $\begin{array}{l}\text { Diâmetro/profundidade de depressões origi- } \\
\text { nadas por moluscos }\end{array}$ & 12,0 & Argilitos & Oregon, EUA \\
\hline
\end{tabular}

As metodologias seguidas por estes autores deram origem a valores que, ou são parciais, pois consideram unicamente alguns dos muitos processos que contribuem para a erosão da plataforma, ou são apenas indicativos, devido à elevada margem de erro que os caracteriza. Serviram, no entanto, para revelar 
que a taxa de rebaixamento das plataformas se situava na ordem dos milímetros por ano e que as novas metodologias a desenvolver deveriam ter em conta essa ordem de grandeza.

Fundamentados nestes resultados, High e Hanna (1970) desenvolveram uma nova metodologia que permitia efectuar medições pontuais em superfícies rochosas com elevado grau de precisão. Dado que não se poderia deixar o equipamento de medição no local, pelas razões apontadas anteriormente, havia que considerar não só a existência de referências fixas e não erodíveis em cada local, como também desenvolver uma técnica que garantisse que cada ponto da superfície rochosa medido em ocasiões sucessivas fosse sempre o mesmo.

Deste modo, aqueles autores desenvolveram um equipamento a que chamaram «Micro Erosion Meter», também conhecido pela sigla MEM (Fig. 1). Para medir a erosão os autores recorreram a um comparador com uma resolução de 0,002 mm, aparelho que, originalmente, era usado unicamente para detectar ínfimas incorrecções no fabrico de peças ou para aferir do seu desgaste posterior. Este comparador era fixado de forma descentrada numa plataforma metálica de forma triangular, que assentava em três pernas cilíndricas. A plataforma e as pernas podiam ser cortadas em aço, embora os autores sugerissem que o aço inoxidável ou o alumínio conferiam ao conjunto maior resistência ao

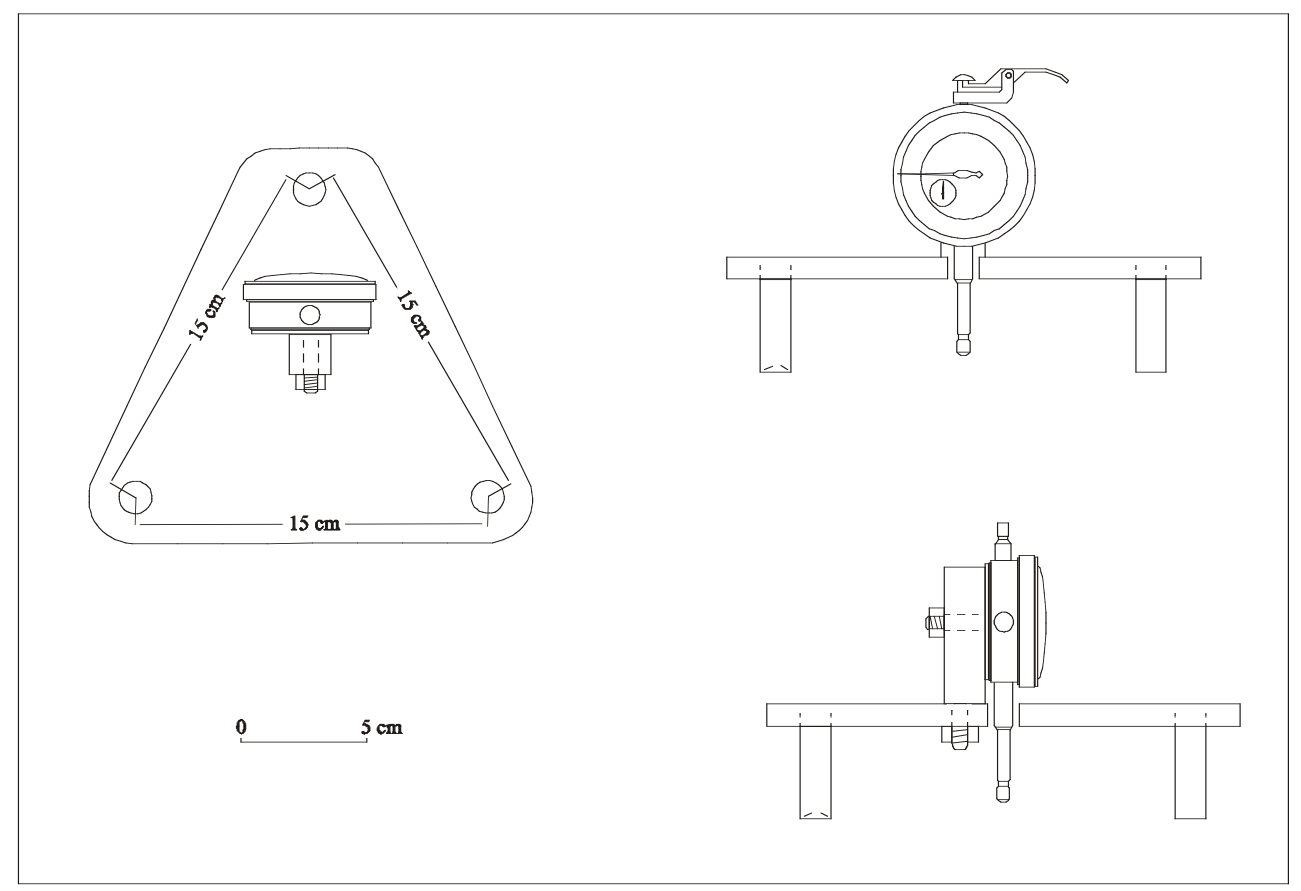

Fig. 1 - Modelo do primeiro MEM (adaptado de High e Hanna, 1970)

FIG. 1 - Model of the first MEM (adapted from HIGH e HANNA, 1970) 
desgaste. Este equipamento era utilizado para efectuar as medições em cada local, sendo logo a seguir recolhido.

Para assegurar que as sucessivas leituras se referissem exactamente aos mesmos pontos da superfície rochosa, eram aí instalados de forma permanente três pinos com topo esférico, em aço inoxidável, que se constituiram assim como as necessárias referências fixas. Seguiram-se, ainda, os princípios do posicionamento cinemático dos Pinos de Kelvin. Assim, as bases das três pernas da plataforma metálica, onde se encontra fixado o comparador, apresentam uma forma diferente. Uma, tem uma depressão cónica com ângulo apical de $120^{\circ}$, outra tem um entalhe em V igualmente com $120^{\circ}$ de ângulo - com o eixo orientado para a perna com base cónica - e, finalmente, a terceira, é completamente plana. Esta opção permite não só garantir de forma precisa a recolocação da plataforma metálica, como também assegurar a sua estabilidade no decorrer do processo de medição.

Os primeiros testes levados a cabo por High e Hanna (1970) foram efectuados em superfícies rochosas localizadas em ambiente fluvial. As conclusões obtidas indicam que o grau de precisão deste equipamento permite obter resultados fiáveis em curtos intervalos de tempo (inferior a dois anos). No entanto, para cada local de medição, este equipamento possibilitava a determinação da erosão de unicamente três pontos da superfície rochosa o que obrigava à multiplicação de locais de medição para obter um conjunto de valores suficientemente extenso para caracterizar com rigor cada área estudada.

Seis anos mais tarde, RoBinson (1976) sugere um conjunto de alterações de pormenor ao MEM, de modo a facilitar a sua utilização em ambientes litorais e, em particular, na medição da erosão em plataformas rochosas. Propõe igualmente alguns métodos estatísticos de análise que, segundo o autor, melhor se adaptariam aos resultados obtidos neste ambiente. Não indica, contudo, quaisquer resultados quantitativos dos ensaios que, seguramente, efectuou. Pertencem assim a TRUDGILL (1976) os primeiros valores publicados de taxas de rebaixamento de plataformas rochosas (Quadro II). Seguindo os mesmos princípios e com equipamentos semelhantes, diversos autores determinaram as taxas de rebaixamento de algumas plataformas rochosas em várias partes do mundo (Quadro II).

A principal limitação do MEM desenvolvido por High e HANNA (1970) - a medição de unicamente três pontos em cada local - esteve na base do desenvolvimento de um novo equipamento, o microerosómetro móvel (Traversing MicroErosion Meter-TMEM), por parte destes autores juntamente com TRUDGILL (TRUdGill et al.,1981) (Fig.2).

Do primeiro MEM foram aproveitados os princípios que garantiam a recolocação da base metálica, exactamente na mesma posição das medições anteriores. A diferença fundamental apresentada por este novo equipamento residia no facto de, agora, o comparador ser independente da base metálica, encontrando-se acoplado a um conjunto formado por 3 braços cilíndricos. Por sua 
QUADRO II - Principais trabalhos publicados contendo valores de taxa de rebaixamento de plataformas rochosas litorais obtidos por intermédio do MEM (adaptado de Trenhaile, 1987, Goudie, 1995 e StephenSON, 2000)

TABLE II - Main published erosion rates on shore platforms measured using the MEM (modified from TRENHAILE, 1987, GOUDIE, 1995 e STEPHENSON, 2000)

\begin{tabular}{|l|c|c|l|l|l|}
\hline \multicolumn{1}{|c|}{ Autor } & $\begin{array}{c}\text { Período } \\
\text { de medição } \\
\text { (anos, meses) }\end{array}$ & $\begin{array}{c}\text { Taxa de } \\
\text { rebaixamento } \\
\left(\mathrm{mm} \mathrm{ano}^{-1}\right)\end{array}$ & \multicolumn{1}{|c|}{ Litologia } & $\begin{array}{c}\text { Posição } \\
\text { reletivamente } \\
\text { à maré }\end{array}$ & \multicolumn{1}{|c|}{ Localização } \\
\hline Trudgill (1976) & 2,0 & $1,01-1,25$ & $\begin{array}{l}\text { Calcários } \\
\text { recifais }\end{array}$ & Supralitoral & $\begin{array}{l}\text { Aldabra Atoll, Oceano } \\
\text { Índico }\end{array}$ \\
\hline Robinson (1977) & 1,0 & $0,0-0,9$ & Xistos argilosos & Mesolitoral & Yorkshire, Inglaterra \\
\hline Kirk (1977) & 2,0 & 1,53 & $\begin{array}{l}\text { Calcários } \\
\text { e argilitos }\end{array}$ & Mesolitoral & $\begin{array}{l}\text { Kaikoura, } \\
\text { Nova Zelândia }\end{array}$ \\
\hline Torunski (1979) & $? ?$ & 0,63 & Calcários & Mesolitoral & $\begin{array}{l}\text { Costa norte do Mar } \\
\text { Adriático }\end{array}$ \\
\hline $\begin{array}{l}\text { Mottershead } \\
(1982)\end{array}$ & 1,0 & 0,61 & Xistos & Supralitoral & $\begin{array}{l}\text { Peninsula de Start-Prawle, } \\
\text { Devon, Inglaterra }\end{array}$ \\
\hline $\begin{array}{l}\text { Gill e Lang } \\
(1983)\end{array}$ & 2,0 & 0,37 & Grauvaques & Mesolitoral & $\begin{array}{l}\text { Costa de Otway, Vitória, } \\
\text { Austrália }\end{array}$ \\
\hline $\begin{array}{l}\text { Viles e Trudgill } \\
(1984)\end{array}$ & 11,0 & 1,97 & Calcários recifais & Supralitoral & $\begin{array}{l}\text { Aldabra Atoll, Oceano } \\
\text { Índico }\end{array}$ \\
\hline $\begin{array}{l}\text { Mottershead } \\
(1989)\end{array}$ & 7,0 & 0,625 & Xistos & Supralitoral & $\begin{array}{l}\text { Peninsula de Start-Prawle, } \\
\text { Devon, Inglaterra }\end{array}$ \\
\hline $\begin{array}{l}\text { Stephenson e } \\
\text { Kirk (1996) }\end{array}$ & 20,0 & 1,48 & $\begin{array}{l}\text { Calcário } \\
\text { e argilitos }\end{array}$ & Mesolitoral & Kaikoura, Nova Zelândia \\
\hline
\end{tabular}

QUADRO III - Principais trabalhos publicados contendo valores de taxa de rebaixamento de plataformas rochosas litorais obtidos por intermédio do TMEM

TABLE III - Main published erosion rates on shore platforms measured using the TMEM

\begin{tabular}{|l|c|c|l|l|l|}
\hline \multicolumn{1}{|c|}{ Autor } & $\begin{array}{c}\text { Período } \\
\text { de medição } \\
(\text { anos, meses })\end{array}$ & $\begin{array}{c}\text { Taxa de } \\
\text { rebaixamento } \\
\left(\mathbf{m m ~ a n o ~}^{-1}\right)\end{array}$ & \multicolumn{1}{|c|}{ Litologia } & $\begin{array}{c}\text { Posição } \\
\text { reletivamente } \\
\text { à maré }\end{array}$ & \multicolumn{1}{|c|}{ Localização } \\
\hline $\begin{array}{l}\text { Trudgill } \text { et al. } \\
(1981)\end{array}$ & 0,4 & 0,2 & Calcários & Mesolitoral & Co. Clare, Irlanda \\
\hline Spencer (1981) & 1,3 & 0,38 & $\begin{array}{l}\text { Calcários } \\
\text { recifais }\end{array}$ & Supralitoral & $\begin{array}{l}\text { Ilhas Caimão, Índias } \\
\text { Ocidentais }\end{array}$ \\
\hline Spencer (1985) & 1,3 & $0,09-1,77$ & Calcários & Supralitoral & $\begin{array}{l}\text { Ilhas Caimão, Índias } \\
\text { Ocidentais }\end{array}$ \\
\hline Stephenson (1997) & 0,3 & 3,6 & Argilitos & Mesolitoral & Kaikoura, Nova Zelândia \\
\hline $\begin{array}{l}\text { Stephenson e } \\
\text { Kirk (1998) }\end{array}$ & 2,2 & 1,13 & $\begin{array}{l}\text { Calcários } \\
\text { e argilitos }\end{array}$ & Mesolitoral & Kaikoura, Nova Zelândia \\
\hline
\end{tabular}




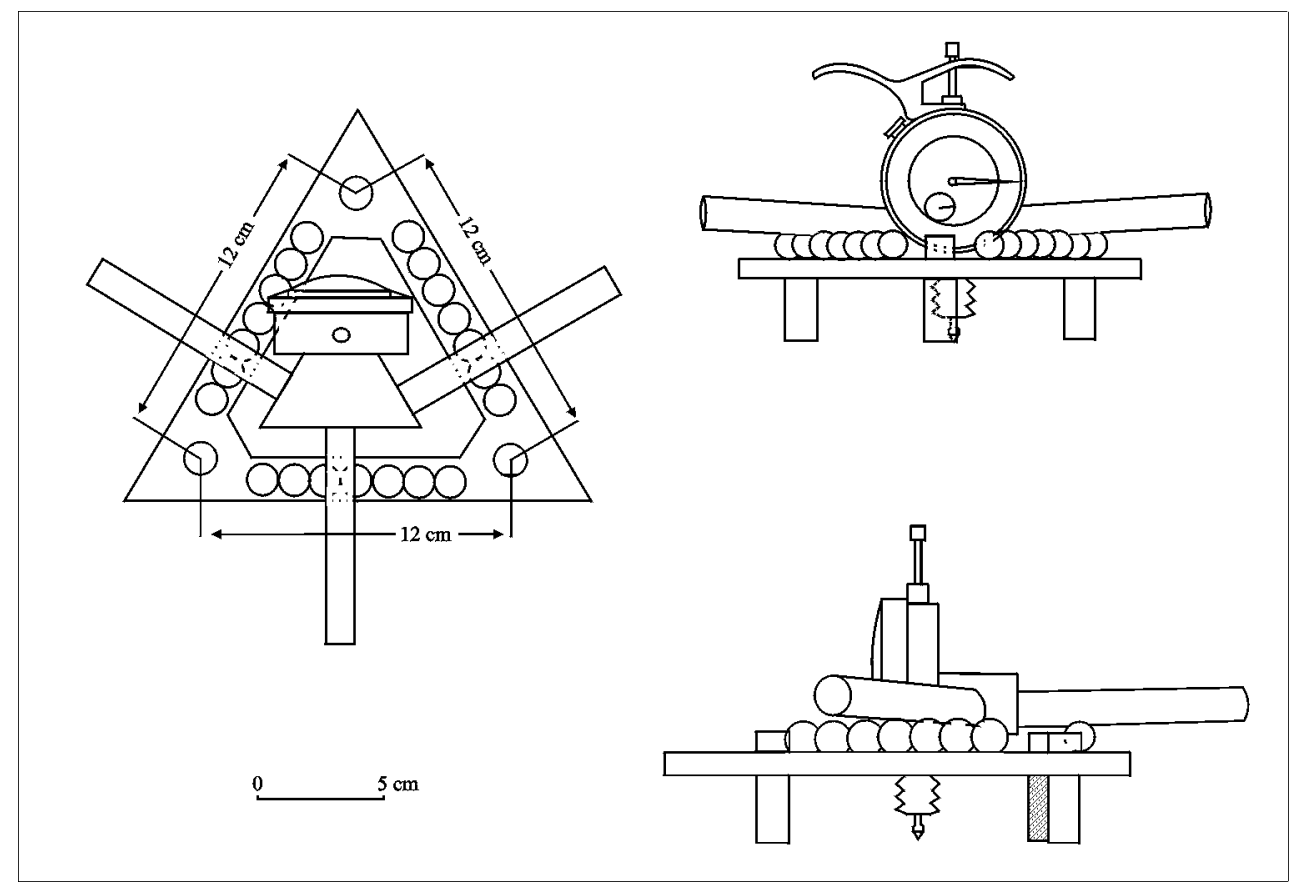

Fig. 2 - Modelo do primeiro TMEM (adaptado de TRUdgiLl et al., 1981)

FIG. 2 - Model of the first TMEM (adapted from TRUDGILL et al., 1981)

vez, a plataforma metálica passou a ser aberta no centro através do qual o comparador efectuava as medições. Para garantir a recolocação nos mesmos pontos medidos anteriormente, os braços cilíndricos que suportavam o comparador assentavam sobre esferas fixas montadas na plataforma metálica. O equipamento desenvolvido por TRUdGILl et al. (1981) permitia efectuar em cada local 27 pontos de medição. Os primeiros ensaios decorreram no litoral ocidental da Irlanda em plataformas rochosas calcárias (Quadro III).

Finalmente, STEPHENSON (1997) propôs modificações no tipo de comparador a utilizar de modo a permitir que a recolha de dados relativos a cada local se processe directamente para um computador portátil. Esta opção justificavase dado que o autor utilizou um TMEM que permitia a leitura de 120 pontos de medição para cada local, facilitando assim a operação de armazenamento de dados. Nos últimos vinte anos, o TMEM foi utilizado em estudos litorais fundamentalmente por investigadores australianos e neozelandeses (Quadro III). 


\section{ESPECIFICAÇÕES DO TMEM DESENVOLVIDO}

Com o objectivo de estudar as plataformas rochosas existentes no litoral português, foi concebido e construído um TMEM pela equipa DILIF do CEG. As características deste equipamento seguem as linhas principais dos TMEM referidos anteriormente, dado que se pretendia comparar os resultados a obter com os já adquiridos por aqueles equipamentos. Contudo, foram introduzidas pequenas alterações que tiveram como objectivos fundamentais:

- melhorar a qualidade de todos os materiais envolvidos, particularmente dos pinos de apoio, para diminuir a margem de erro admissível;

-redimensionar o equipamento de forma a possibilitar o reposicionamento dos pinos de apoio para aumentar o grau de confiança na sua estabilidade em todas as fases de medição;

- aumentar o número de pontos medidos em cada local;

O TMEM desenvolvido é, assim, constituído por um conjunto de elementos fabricados em aço inoxidável do tipo mais resistente ao ambiente marinho - o aço A4 (AISI 316) - e tem as características que de seguida se descrevem:

\section{Comparador}

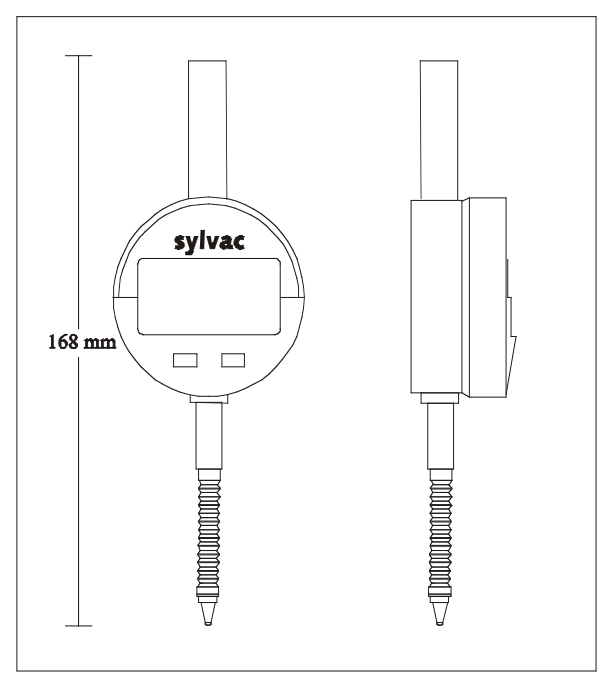

FIG. 3 - Comparador utilizado no TMEM desenvolvido

FIG. 3 - Dial gauge employed in the TMEM described in this paper
De entre os vários aparelhos existentes no mercado foi escolhido um comparador digital do fabricante suiço SyLVAC - Fig. 3, com ponta esférica em carboneto de tungsténio. Este aparelho tem uma capacidade de medida de 0,001 a 25,000 $\mathrm{mm}$ e apresenta uma resolução - 0,001 mm - superior à recomendada por High e Hanna (1970). Possui igualmente a capacidade de ligação a um computador por intermédio de um cabo óptico RS 232. Os dados podem deste modo ser imediatamente armazenados numa folha de cálculo dum computador portátil, utilizando software fornecido com o comparador.

\section{Suporte do Comparador}

O comparador encontra-se acoplado a uma peça de secção cilíndrica com $60 \mathrm{~mm}$ de diâmetro e $16 \mathrm{~mm}$ de altura. 


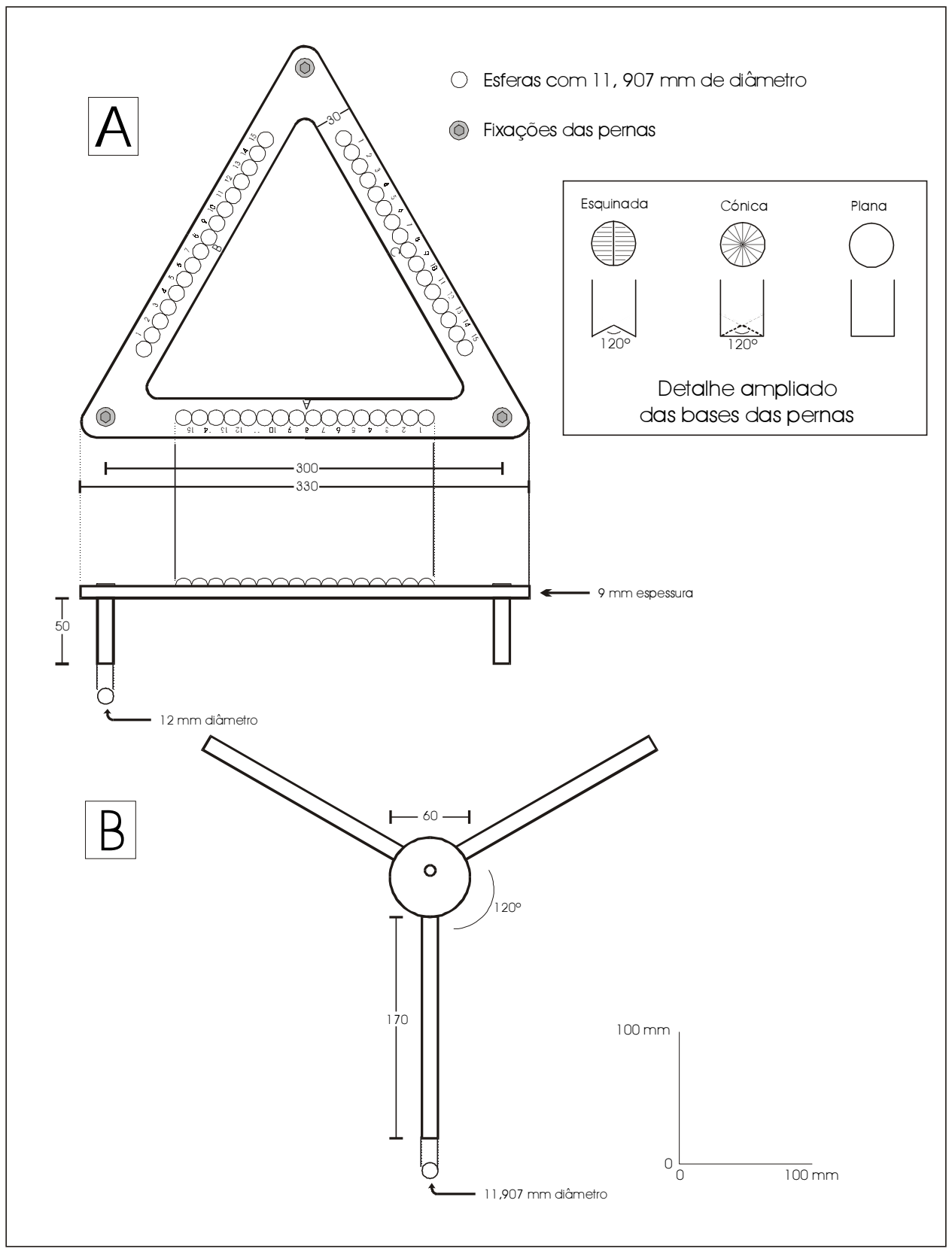

FIG. 4 - Desenho detalhado do TMEM desenvolvido. A - Plataforma metálica; B: - Suporte do Comparador

FIg. 4 -Detailed draw of the TMEM described in this paper. A-Base plate; $B$-Dial gauge support 
Desta peça saem 3 braços cilíndricos com 11, $907 \mathrm{~mm}$ de diâmetro e $170 \mathrm{~mm}$ de comprimento, dispostos num plano horizontal com $120^{\circ}$ de afastamento entre si (Fig. 4).

\section{Plataforma metálica}

A plataforma metálica onde o conjunto anteriormente descrito vai assentar é talhada numa placa com $9 \mathrm{~mm}$ de espessura. Tem a forma de uma moldura triangular equilátera com $330 \mathrm{~mm}$ de lado e apresenta os vértices exteriores e interiores boleados. Em cada um destes lados foram escavadas 16 depressões circulares onde foram coladas igual número de esferas de aço. As esferas de aço apresentam um diâmetro igual ao dos braços que suportam o comparador, $11,907 \mathrm{~mm}$. Toda a montagem das esferas foi uma operação de precisão que permitiu garantir que:

- o conjunto de 16 esferas de cada lado esteja colocado exactamente à mesma distância dos vértices respectivos;

- o centro das esferas se encontre alinhado ao longo de um eixo disposto a igual distância dos lados da moldura triangular;

- que este eixo pertença ao plano da face de cada lado da moldura, de maneira que cada esfera apresente metade para o exterior;

- que os topos das esferas se encontrem todos colocadas à mesma altura.

Aos lados da moldura triangular foram posteriormente atribuídos as letras $\mathrm{A}, \mathrm{B}$ e $\mathrm{C}$, enquanto os espaços entre as esferas foram numerados de $1 \mathrm{a}$ 15. Ambas as marcações seguiram o sentido do ponteiro dos relógios. Deste modo, cada espaço entre as esferas terá uma referência do tipo A1, A2 ...B1, $\mathrm{B} 2 \ldots \mathrm{C} 1, \mathrm{C} 2$.

Junto aos vértices, a exactamente $300 \mathrm{~mm}$ de distância entre si, foram fixadas - simultaneamente por parafuso e cola - as três pernas cilíndricas diâmetro de 11,907 mm - do TMEM. Cada perna apresenta uma base diferente. Uma é cónica, outra esquinada e a terceira é plana (fig. 4), aplicando-se, tal como em High e Hanna (1970), os princípios do posicionamento cinemático dos Pinos de Kelvin. Nos MEM e TMEM desenvolvidos, respectivamente por HigH e Hanna (1970) e TRUdGill et al. (1981), a ponta do comparador na sua posição mais distendida (valor 0,000 $\mathrm{mm}$ ) ficava abaixo do nível da base das pernas. Este facto significava que, na fase final de medição em cada local, o topo dos pinos se encontrava acima do nível da superfície rochosa, ficando assim sujeito a modificações da sua posição original provocadas quer por pancadas de calhaus ou de blocos rochosos (naturais num ambiente tão dinâmico como este) quer por actos de vandalismo. Para ultapassar este problema, a base das pernas do TMEM agora apresentado encontra-se $5 \mathrm{~mm}$ abaixo da ponta do comparador 


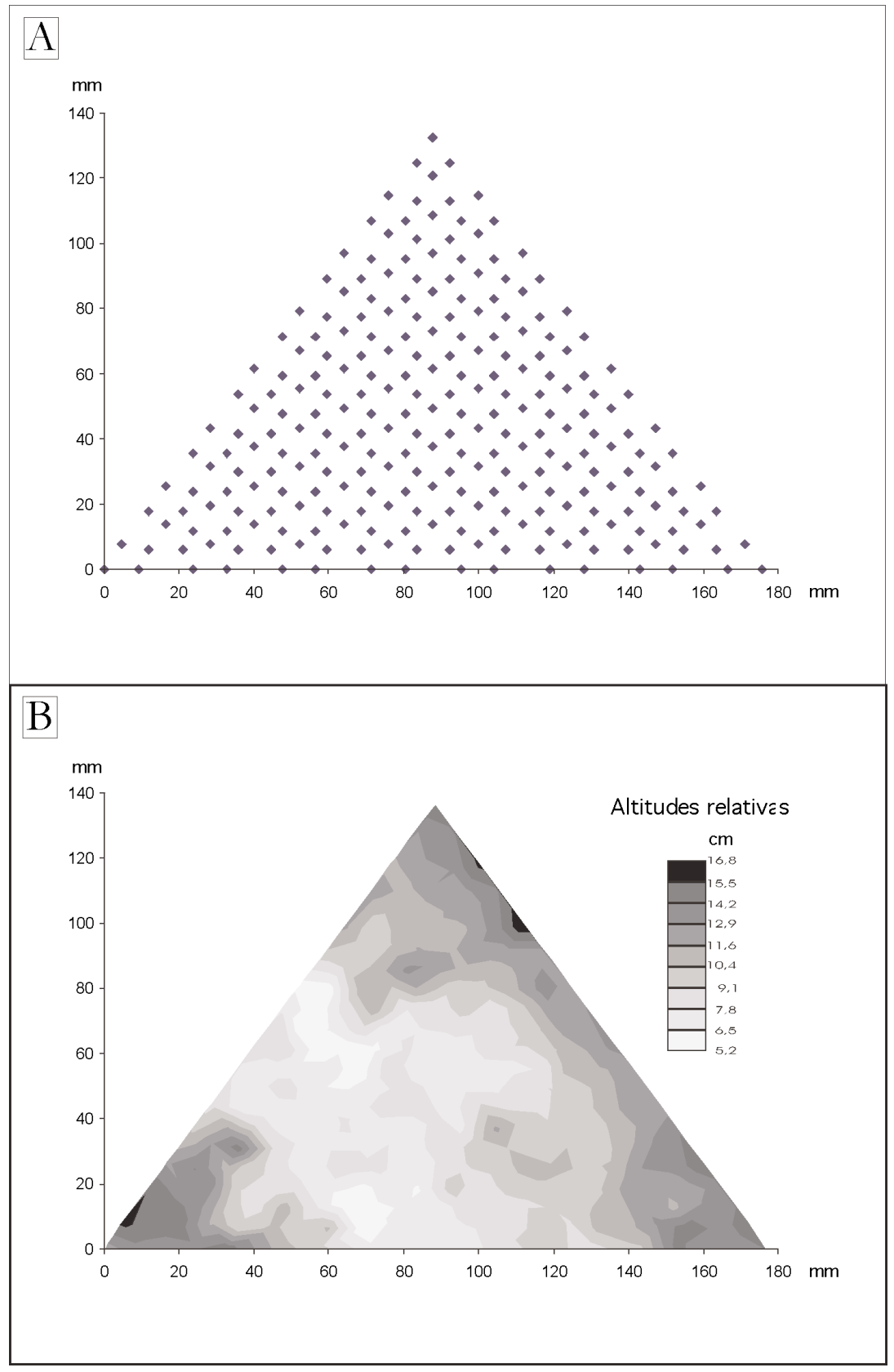

FIG. 4 - A - Pontos de leitura em cada local de medição; B - Modelo digital de terreno do local de ensaio TMEM nos Tombadoiros (29/10/2000)

FIG. 4-A-Measuring points for each site; $B$-Digital terrain model of the TMAM test site at Tombadoiros (29/10/2000) 
na sua posição mais distendida, permitindo assim que os pinos se encontrem sempre em segurança abaixo da superfície rochosa.

As opções tomadas na concepção do suporte do comparador anteriormente descrito e da plataforma metálica permitem que, para cada local, se possam efectuar um total de 255 pontos de medição numa área de $116,7 \mathrm{~cm}^{2}$ (fig. $5 \mathrm{~A}$ ). Este valor representa um incremento significativo relativamente ao equipamento que até agora permitia o maior número de pontos de medição - o TMEM de Stephenson com 120 pontos, fornecendo assim uma maior exactidão nos resultados a obter em cada local.

\section{Pinos de apoio}

Os pinos de apoio são compostos por um varão de rosca ao qual se fixou com cola epóxida uma porca de mama, fornecendo assim um topo esférico sobre o qual vão assentar as pernas da plataforma metálica. Os pinos são depois inseridos numa bucha metálica fomando um conjunto geralmente designado por «fixação pesada».

A possibilidade de medir com exactidão a erosão depende em grande parte da estabilidade destes pinos. Esta estabilidade é garantida não só pela posição em que estes são colocados, como referimos atrás, mas também pelo tipo de material a utilizar. Vários autores, entre os quais TRUDGILl et al. (1981), KIRK (1977), Viles e Trudgill (1984) e STEPHENSON e KirK (1996), referem problemas com locais de medição devidos à destruição dos pinos de apoio. Na maior parte dos casos, estes autores utilizaram pinos de aço inoxidável fixados à rocha por intermédio de buchas em aço simples. Em função destes resultados, optámos por utilizar tanto os pinos como as buchas exclusivamente em aço inoxidável de tipo A4.

\section{Placa de calibração}

Finalmente, com o objectivo de permitir verificar a precisão do comparador foi construída uma placa de calibração triangular no mesmo tipo de aço inoxidável que o restante equipamento. Esta placa possui em cada vértice porcas

com batente inox de $6 \mathrm{~mm}$ idênticas às cabeças dos pinos sobre as quais é possível colocar a plataforma metálica e o suporte do comparador.

\section{PROCEDIMENTOS DE INSTALAÇÃO E MEDIÇÃO SEGUIDOS}

\section{Instalação dos pinos}

As características do equipamento condicionaram, de certa forma, os locais a monitorizar dado que somente em superfícies horizontais ou com fraco declive $\left(<10^{\circ}\right)$ se pode garantir a estabilidade tanto da colocação dos braços que 
suportam o comparador sobre a plataforma metálica, como a colocação desta sobre os pinos. No entanto, convém referir que, aplicando procedimentos complementares, é possível efectuar medições em superfícies rochosas com maior declive: TRudgill et al. (1981) faz inclusivamente referência a medições efectuadas com sucesso em superfícies verticais.

Escolhido o local e abertos os buracos com um berbequim, os pinos foram apertados nas buchas. Este conjunto beneficiou ainda de uma fixação suplementar fornecida pela cola epóxida que previamente foi introduzida nos buracos. Por outro lado, a operação de instalação dos pinos foi efectuada de modo a deixar protegidas as áreas de medição, dado que se pretende introduzir o mínimo de perturbação no ritmo de evolução natural do sector a estudar. A esse propósito, deverá ser tomado em linha de conta que, por mais cuidados de que se revista esta operação, ela é em si um factor de instabilização da rocha. Pretende-se, pois, na continuação desta investigação, verificar se os pontos de medição localizados mais perto dos pinos sofrem maior taxa de erosão.

Para protecção dos pinos entre cada medição, selaram-se os buracos, onde estes estão instalados, utilizando para o efeito massa de silicone. Esta operação deve ser efectuada dando tempo de secagem suficiente a esta massa antes da subida da maré. A tampa assim criada proporciona uma protecção eficaz tendo ainda a vantagem de poder ser reutilizada múltiplas vezes.

\section{Medições}

Cada medição é precedida de um conjunto de cuidados respeitantes não só ao equipamento como também ao próprio local de medição, essenciais para diminuir o erro de operação.

Nesse sentido, algum cuidado é posto na escolha dos dias e horas para efectuar as campanhas de medição. Efectivamente, estudos de laboratório efectuados por SPATE et al. (1985) concluem que variações de temperatura do ar entre $4^{\circ}$ e $25^{\circ} \mathrm{C}$ originaram diferenças de $0,006 \mathrm{~mm}$ nos valores obtidos pelo MEM utilizado. Embora os autores considerem esta ordem de erro pouco significativa no cálculo de rebaixamento das plataformas rochosas litorais, na investigação em curso pretende-se efectuar todas as medições em condições de temperatura semelhantes, procedimento que já foi seguido nas campanhas efectuadas. Por outro lado, previamente às campanhas de medição efectuadas, aferiu-se o comparador utilizando para o efeito a placa de calibração já referida anteriormente.

No local, torna-se necessário limpar cuidadosamente as cabeças esféricas dos pinos antes da instalação da placa metálica. É ainda necessário limpar a área a medir. Não se deve utilizar, em nenhuma circunstância, material abrasivo. Um pincel grosso deverá ser suficiente.

A plataforma metálica é pousada nos pinos utilizando sempre a seguinte sequência: primeiro a perna com a base cónica, seguidamente a perna com a base esquinada e, por último, a perna com a base plana. A orientação da perna 
cónica é sempre indicada junto com os primeiros valores de cada local de medição, dado que a recolocação da plataforma metálica em cada local se manterá inalterável.

Os braços, onde se encontra acoplado o comparador, devem então assentar sobre as esferas da plataforma metálica. No entanto, a posição de cada braço deve ser sempre perpendicular ao lado onde está apoiado, pois noutras posições os braços não assentam bem podendo inclusivamente resvalar. Para garantir esta perpendicularidade aplicou-se a metodologia seguida primeiro por TRUdGiLl et al. (1981), e mais tarde por STEPHENSON (1997) que indica que, para o tipo de MEM utilizado neste trabalho de investigação, a soma das posições de cada braço deve ter sempre o valor $24(\mathrm{Ex}$ : $\mathrm{A} 1+\mathrm{B} 8+\mathrm{C} 15=24)$. Este valor está dependente do número de esferas existentes em cada lado. Beneficiando da localização excêntrica do comparador relativamente aos braços, cada posição do conjunto braços/comparador permite efectuar três leituras diferentes, com o comparador orientado em primeiro lugar para o lado A, depois para o B e finalmente para o $\mathrm{C}$, possibilitando obter valores para 255 pontos de medição diferentes. A leitura do conjunto destes pontos por um utilizador experimentado consome cerca de 30 minutos. Seguindo uma tabela de posições previamente calculada efectua-se cada medição, pousando suavemente a ponta do comparador. Deste modo, diminui-se o desgaste da ponta e impede-se que esta provoque erosão na superfície rochosa. A folha de resultados obtida é idêntica à apresentada no Quadro IV.

QUADRO IV - Exemplo de parte de uma folha com a localização dum ponto de medição TMEM, as referências para a posição dos braços do equipamento e as medições efectuadas (em mm)

TABLE IV-Example of a TMEM site spread sheet with references to the TMEM arms position and part of the collected data (in $\mathrm{mm}$ )

\begin{tabular}{|c|c|c|c|c|c|c|c|c|c|c|c|}
\hline \multirow{2}{*}{\multicolumn{4}{|c|}{$\begin{array}{lr}\text { Local: } \quad \text { Tombadoiros } \\
\text { Perna cónica: para leste }\end{array}$}} & \multicolumn{2}{|c|}{ Ponto: } & \multicolumn{2}{|c|}{ T1C1 } & \multicolumn{2}{|c|}{ Data: } & \multicolumn{2}{|c|}{$29 / 10 / 2000$} \\
\hline & & & & & & & & & & & \\
\hline \multicolumn{4}{|c|}{ Referência $\mathbf{A}$} & \multicolumn{4}{|c|}{ Referência B } & \multicolumn{4}{|c|}{ Referência C } \\
\hline $\mathbf{A}$ & B & $\mathbf{C}$ & medições & B & C & $\mathbf{A}$ & medições & C & $\mathbf{A}$ & B & medições \\
\hline 1 & 8 & 15 & 13,818 & 1 & 8 & 15 & 12,904 & 1 & 8 & 15 & 14,697 \\
\hline 2 & 8 & 14 & 14,471 & 2 & 9 & 13 & 12,256 & 2 & 8 & 14 & 12,958 \\
\hline 2 & 9 & 13 & 14,820 & 2 & 8 & 14 & 12,249 & 2 & 9 & 13 & 15,364 \\
\hline 3 & 7 & 14 & 13,059 & 3 & 10 & 11 & 10,307 & 3 & 7 & 14 & 13,258 \\
\hline 3 & 8 & 13 & 9,961 & 3 & 9 & 12 & 9,222 & 3 & 8 & 13 & 11,962 \\
\hline 3 & 9 & 12 & 10,680 & 3 & 8 & 13 & 10,760 & 3 & 9 & 12 & 13,410 \\
\hline 3 & 10 & 11 & 9,699 & 3 & 7 & 14 & 12,559 & 3 & 10 & 11 & 11,769 \\
\hline 4 & 7 & 13 & 10,975 & 4 & 11 & 9 & 7,705 & 4 & 7 & 13 & 10,970 \\
\hline. & & & & & & & & .. & & .. & \\
\hline 15 & 1 & 8 & 13,938 & 15 & 1 & 8 & 13,630 & 15 & 1 & 8 & 15,899 \\
\hline
\end{tabular}


Com o auxílio da placa de calibração, calculou-se a margem de erro possível em cada medição. Considerando as características do equipamento desenvolvido e o conjunto de procedimentos seguidos nas fases de instalação e medição, estima-se a margem de erro em 0,005 mm.

Outros pormenores de instalação, bem como procedimentos mais específicos podem ser consultados em High e Hanna (1970), Trudgill et al. (1981), Spate et al. (1985), Robinson (1976), STEPHENSON e KiRK (1996) e STEPHENSON (2000).

\section{PRIMEIROS RESULTADOS DE ESTUDO EXPERIMENTAL}

Os primeiros ensaios experimentais decorreram em plataformas rochosas da Estremadura portuguesa. A primeira área para a qual se obtiveram resultados comparativos situa-se cerca de $2 \mathrm{~km}$ a norte da Ericeira, num local conhecido por Tombadoiros. É um sector de litoral rochoso exposto a oeste e talhado numa alternância de argilas, calcários e arenitos. A arriba, com cerca de 15 metros de altura, contacta com o mar por intermédio de um conjunto de plataformas rochosas desniveladas, talhadas em calcário bastante resistente valor R de 53,3 obtido com o Martelo de Schmidt. Estas plataformas são fundamentalmente sub-estruturais apresentando um declive 5N340. O sector escolhido encontra-se a cerca de 3,1 m acima do zero hidrográfico, entre o nível mínimo da preiamar morta e o nível máximo da preiamar viva. Apresenta as mesmas características da plataforma onde está inserido, com excepção do declive que é ligeiramente inferior aqui $-4,1^{\circ}$.

A instalação dos pinos de apoio e a primeira medição foi levada a cabo no dia 29 de Outubro de 2000. Juntando os valores de altura relativos à máxima extensão do comparador (correpondendo ao valor $0,000 \mathrm{~mm}$ ) às duas dimensões anteriormente determinadas (Fig. 5A) para cada ponto de medição, foi possível elaborar um mapa digital de terreno (Fig. 5B) com um elevado grau de detalhe. A prolongada situação atmosférica instável que se tem feito sentir em Portugal nos últimos meses só permitiu a realização de uma segunda medição nos Tombadoiros em 2 de Fevereiro de 2001, ou seja 96 dias depois.

Os primeiros resultados obtidos apontam para uma taxa de rebaixamento médio que, numa primeira análise, aparenta ser muito reduzida (Quadro V). No entanto, se compararmos estes resultados com os alcançados pelos investigadores que calcularam a taxa de erosão de plataformas calcárias, concluímos que eles não diferem significativamente dos alcançados por TRUDGILL et al. (1981) para a Irlanda, o único daqueles estudos que foi realizado num ambiente litoral semelhante ao ocorrido em Portugal durante o período da presente medição.

Uma outra explicação para aquele valor poderá residir no facto da haloclastia, principal processo a actuar nesta faixa litoral, como referem os estudos de Saumell et al. (1982), Trenhaile (1987), e Goudie e Viles (1997), ser mais activa no Verão devido ao aumento da evaporação. MotTERSHEAD (1989) calcula 
mesmo esta diferença, indicando que a taxa de rebaixamento da plataforma supralitoral por este autor estudada apresentava no Verão valores médios 2 a 3 vezes superiores (podendo mesmo atingir valores 6 vezes superiores nos Verões mais quentes) aos do Inverno.

QUADRo V - Resultados globais das medições efectuadas com o TMEM na plataforma rochosa litoral dos Tombadoiros

TABLE V-Global results of the TMEM measurements at the Tombadoiros shore platform

\begin{tabular}{|c|c|c|}
\hline Tombadoiros & \multicolumn{2}{|c|}{ Rebaixamento da plataforma } \\
\hline & $\begin{array}{c}\text { Entre } 29 / 10 / 2000 \\
\text { e } 02 / 02 / 2001\end{array}$ & $\begin{array}{c}\text { Taxa anual } \\
\text { (mm/ano) }\end{array}$ \\
\hline Valor Médio & $-0,040$ & $-0,153$ \\
\hline
\end{tabular}

Para além disso, o local de medição sofreu uma modificação significativa entre a $1 .^{\mathrm{a}}$ e a $2 .^{\mathrm{a}}$ medições. Assim, em Outubro de 2000, a superfície rochosa encontrava-se limpa, sem qualquer ocupação biológica fixa. Pelo contrário, em Fevereiro, 58\% dos pontos de medição encontravam-se cobertos por um líquene característico desta faixa litoral, a Verrucaria maura. Segundo TrenhaILE (1987) estes líquenes actuam como desagregadores da rocha, e, portanto, originadores de bioerosão. É possível, no entanto, que numa fase inicial, o crescimento deste líquene sobre a rocha seja mais significativo que a erosão que ele provoca.

Nesse sentido, tornou-se necessário determinar a influência da Verrucaria maura nos valores recolhidos no local em 02/02/2001. Deste modo, nesta campanha, para além das medições, identificaram-se igualmente os pontos em que se registava a presença daquele líquene.

Os resultados obtidos (Quadro VI) apontam para uma taxa de rebaixamento claramente inferior nos pontos ocupados pela Verrucaria maura. Registam-se inclusivamente valores positivos, que correspondem a pontos onde ocorreu acreção na plataforma. O problema levantado pela ocupação deste líquene não é o único que se coloca à análise dos resultados obtidos. Outros estudos respeitantes à microtopografia e microlitologia estão em curso, sendo, para já, prematuro avançar mais alguma conclusão.

\section{CONCLUSÕES}

O microerosómetro descrito é um equipamento fundamental na determinação exacta da taxa de erosão das superfícies rochosas em curtas escalas temporais. O desenho, a construção e a instalação de todo este equipamento obriga não só a uma rigorosa atenção, como à utilização dos materiais adequados de molde a garantir que o conjunto seja estável e resistente. Só assim se poderá diminuir 
QUADRO VI - Resultados agrupados das medições efectuadas com o TMEM na plataforma rochosa litoral dos Tombadoiros

TABLE VI-Grouped results of the TMEM measurements at the Tombadoiros shore platform

\begin{tabular}{|r|c|c|c|c|}
\hline \multirow{3}{*}{ Tombadoiros } & \multicolumn{4}{|c|}{ Rebaixamento da plataforma } \\
\cline { 2 - 5 } & \multicolumn{2}{|c|}{ Entre 29/10/2000 e 02/02/2001 } & \multicolumn{2}{|c|}{ Taxa anual (mm/ano) } \\
\cline { 2 - 5 } & \multicolumn{2}{|c|}{ Sector de rocha } & \multicolumn{2}{c|}{ Sector de rocha } \\
\cline { 2 - 5 } & limpa & $\begin{array}{c}\text { com Verrucaria } \\
\text { maura }\end{array}$ & limpa & $\begin{array}{c}\text { com Verrucaria } \\
\text { maura }\end{array}$ \\
\hline Valor Médio & $-0,061$ & $-0,025$ & $-0,233$ & $-0,096$ \\
\hline Valor mínimo & $-0,001$ & $+0,033$ & $-0,004$ & $+0,125$ \\
\hline Valor máximo & $-0,219$ & $-0,180$ & $-0,833$ & $-0,684$ \\
\hline
\end{tabular}

a margem de erro sempre presente em medições desta ordem de valores efectuadas no campo e, deste modo, ter confiança nos resultados obtidos.

O TMEM permite monitorizar vários locais com um único equipamento. Por outro lado, não implica acompanhamento contínuo, dado que as medições

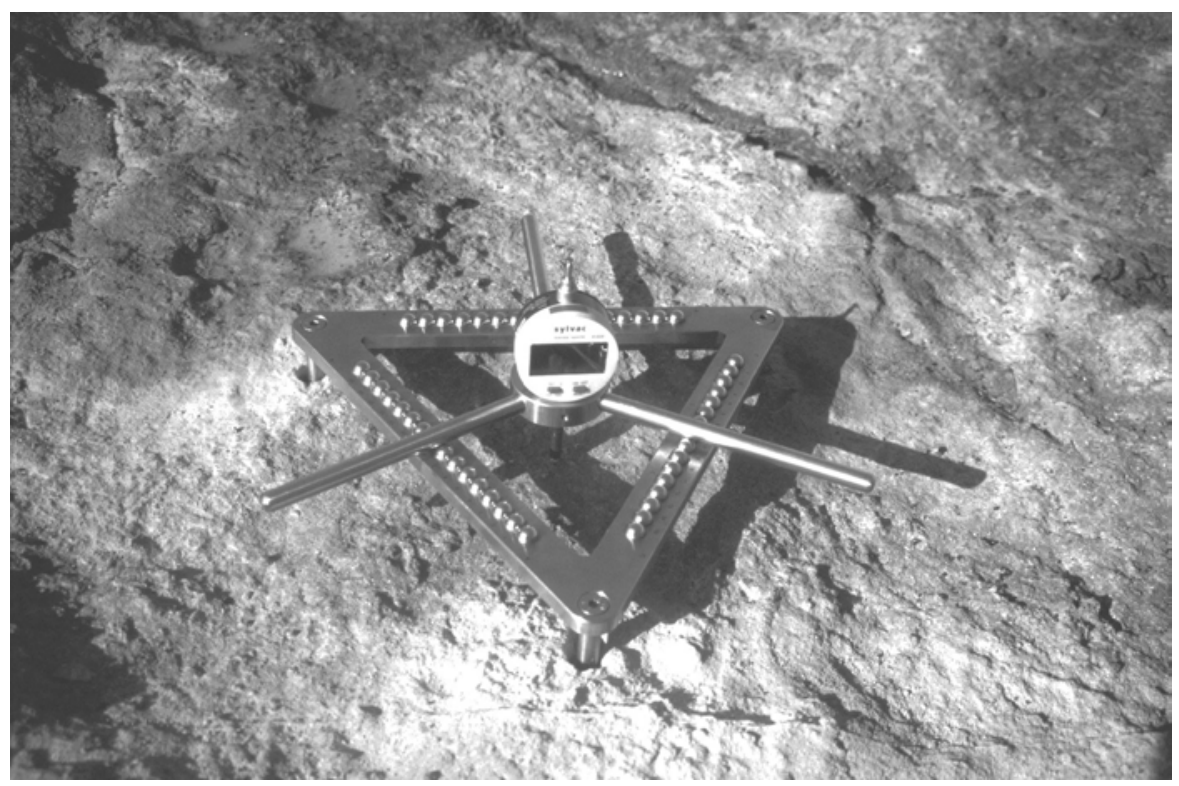

Fото 1 - TMEM na plataforma rochosa litoral dos Pното 1 - TMEM on the shore platform of Tombadoiros (29/10/2000) 
são pontuais, sendo assim indicado para locais com acessibilidade complicada, onde observações frequentes seriam difíceis.

A aplicação do TMEM às plataformas rochosas litorais, como os primeiros resultados desta investigação indicam, pode ser um auxiliar precioso para a investigação sobre os vários processos que contribuem para a evolução destas formas de relevo.

Para além disso, este equipamento, embora desenvolvido tendo em atenção os constrangimentos litorais, pode ser aplicado a outros tipos de ambiente - de montanha, margens de cursos de água (DrYSDALE e GILliEson,1997) - e até no estudo sobre a deterioração dos edifícios (COOKE e DooRnKAMP,1990).

Apresenta, no entanto, algumas limitações que convém também referir: só se pode utilizar em rochas bem consolidadas, dado que em rochas pouco coerentes é difícil conseguir a rigidez necessária para a fixação dos pinos metálicos; os resultados obtidos representam a taxa de erosão de um local exacto da plataforma, de modo que, para calcular a erosão média de uma área, é necessário ter o cuidado de multiplicar os pontos de medição. No seguimento do ensaio experimental, multiplicar-se-ão os locais de medição e proceder-se-á ao tratamento estatístico mais aprofundado dos resultados.

\section{AGRADECIMENTOS}

Ao Prof. Wayne Stephenson, investigador neozelandês, pela partilha da experiência acumulada com a utilização de microerosómetros, que ajudou a consolidar as opções tomadas.

Ao Eng. António Mouta, de firma Euroiso, pelas sugestões preciosas na concepção do equipamento - em particular na peça de secção cilíndrica que agrega os três braços e o comparador, inteiramente da sua autoria-e pelo cuidado posto na construção do mesmo.

Aos Drs. Carla Mora, Gonçalo Vieira e Ricardo Garcia pela colaboração na instalação dos primeiros pontos de medição.

Ao Prof. César Andrade pela atenta leitura do texto e pelas sugestões apresentadas.

\section{BIBLIOGRAFIA}

CoOKe, R.; DoornKamp, J. (1990) - Geomorphology in Environmental Management. Clarendon Press, Oxford.

Drysdale, R.; Gillieson, D. (1997) - Micro-erosion Meter Measurements of Travertine Deposition rates: a Case study from Louie Creek, Northwest Queensland, Australia. Earth Surface Processes and Landforms, 22: 1037-1051.

Goudie, A. (1995) - The Changing Earth. Rates of Geomorphological Processes. Blackwell, Oxford. 
Goudie, A.; Viles, H. (1997) - Salt Weathering Hazards. John Wiley \& Sons, Chichester.

High, C. J.; Hanna F. K. (1970) - A Method for the Direct Measurement of Erosion on Rock Surfaces. British Geomorphological Research Group Technical Bulletin, 5: 1-25.

Hodgkins, P. (1964) - Rate of erosion on intertidal limestone. Zeitschrift für Geomorphologie, 8, Berlin-Stuttgart: 385-392

KIRK, R.M. (1977)-Rates and Forms of Erosion on Intertidal Platforms at Kaikoura Peninsula, South Island, New Zealand. New Zealand Journal of Geology and Geophysics, 20: 571-613.

Mottershead, D. N. (1989) - Rates and Patterns of Bedrock Denudation by Coastal Salt Spray Weathering: A Seven Year Record. Earth Surface Processes and Landforms, 14: 383-398.

Revelle, R.; Emery, K. (1957) - Chemical erosion of beach rock and exposed reef rock. US Geological Survey Professional Paper 260-T: 699-709.

Robinson, L. A. (1976) - The Micro-erosion Meter Technique in a Littoral Environment. Marine Geology, 22:M51-M58.

Spate, A.; Jennings, J.; Smith, D.; Greenaway, M. (1985) - The Micro-Erosion Meter: use and limitations. Earth Surface Processes and Landforms, 10: 427-440.

Saumell, E.; Belles, J.; cueva, A. (1982) - Carst marino: estado de la cuestion. Estudios Geográficos, 43: 411-438.

Stephenson, W. (1997) - Improving the Traversing Micro-Erosion Meter. Journal of Coastal Research, 13 (1): 236-241.

Stephenson, W. (2000) - Shore platforms: a neglected coastal feature?. Progress in Physical Geography, 24 (3): 311-327.

Stephenson, W. J.; KIRK, R. M. (1996) - Measuring Erosion Rates Using the Micro Erosion Meter: 20 Years of Data From Shore Platforms, Kaikoura Peninsula, South Island New Zealand. Marine Geology, 131:209-218.

Trenhaile, A. (1987) - The Geomorphology of rock coasts. Clarendon Press, Oxford.

Trudgill, S. T. (1976) - The Subaerial and Subsoil Erosion of Limestone at Aldabra Atoll, Indian Ocean. Zeitschrift für Geomophologie Supplementband, 26: 201-210.

Trudgill, S.; High, C. J.; Hanna, F. K. (1981) - Improvements to the Micro-Erosion Meter. British Geomorphological Research Group Technical Bulletin, 29: 3-17.

Viles, H. A; Trudgill, S. T (1984) - Long Term Remeasurements of Micro-erosion Meter Rates, Aldabra Atoll, Indian Ocean. Earth Surface Processes and Landforms, 9: 89-94. 